\title{
COVID-19: Transmission, Incubation and Iceberg Phenomenon
}

\author{
Agnishikha.M.Patwardhan ${ }^{1}$, Dr. Swaroopa Chakole ${ }^{2}$ \\ ${ }^{1}$ Intern, Dept. of Community Medicine, Jawaharlal Nehru Medical College, Datta Meghe Institute of Medical \\ Sciences (Deemed to be University), Sawangi (Meghe), Wardha-442001, Maharashtra, India, \\ ${ }^{2}$ Professor, Dept. of Community Medicine, Jawaharlal Nehru Medical College, Datta Meghe Institute of \\ Medical Sciences (Deemed to be University), Sawangi (Meghe), Wardha-442001, Maharashtra, India, \\ emails: ${ }^{1}$ agnipatwardhan@gmail.com, ${ }^{2}$ drswaroopachakole@gmail.com, \\ Type of Article: Review \\ Conflict of Interest: None \\ Funding: DMIMS \\ Ethical Approval: IEC, DMIMS, Wardha.
}

\begin{abstract}
BACKGROUND

The COVID-19 has destroyed in men and money as well. The casualty as well as the economy suffered so much that it must be contained as soon as possible and by all means.

SUMMARY

The pathophysiology needs to be carefully examined in case of coronavirus which causes the COVID-19 infection. The mutated virus said to be more virulent so more research is needed in order to study the virus effect. The iceberg phenomenon in case of COVID-19 is necessary to take into account and testing of all the patients must be done to ensure the negative reports. Also, man animal conflicts and human nature interaction must be so managed that bot have win win situation as the COVID-19 is not the last pandemic that world has seen.
\end{abstract}

\section{CONCLUSION}

It is important to be aware regarding deterioration of the nature due to human ventures. More study on the iceberg phenomenon in terms of COVID-19 and its applicability should be done in order to redesign the mitigating measures.

KEYWORDS:COVID-19, ICEBERG PHENOMENON, MUTATION, PATHOPHYSIOLOGY, INCUBATION PERIOD, VIRULENCY.

\section{INTRODUCTION}

The coronavirus disease 2019 or COVID19 is the lethal pandemic that broke out as outbreak in Wuhan city of the Hubei province in China(1). The outbreak then turned epidemic and started to spread like wild fire. The newly identifies coronavirus is behind this menace. The coronavirus has spike proteins and looks like crown therefore it has been named as coronavirus. The previous outbreak from the coronavirus family was contained to certain geographical locations and were mitigated in time before spreading to the whole world. But the new member in the coronavirus family, the novel coronavirus has been proving extremely contagious and lethal in terms of case fatalities due to disease which is caused by the coronavirus namely COVIS-19. Till December 26, 2020, the registered infected cases of the COVID-19 pandemic rose to $79,925,965$ and case fatalities due to COVID-19 till date stands at 1,752,013 crossing the unfortunate one million $\operatorname{mark}(2)$. Top countries reeling under pressure of the case burden are United States of America, India, Brazil, Russian federation, France and United Kingdom. They accounts almost half of the cases worldwide(3). The new strain of the mutated coronavirus has been reported in United Kingdom and reportedly present in ten other European countries. Another mutated strain of the coronavirus was reported in South Africa(4). Both the strain is more virulent 
than the previous strain of the coronavirus. The factor which highly influences the clinical outcome is the patient's condition and its underlying illness that is comorbidity. The underlying medical condition is itself hard to treat if its chronicaland when combined with the COVID-19 infection, it may prove fatal(5). Structure of the coronavirus has spikes on it as frequently seen on graphics and has crown shaped. Transmission of the virus is the main challenge to contain and is extremely virulent. Its rapid rate of transmission makes it difficult to trace. The model used to mitigate the viral spread is test, trace and treat. The iceberg phenomenon or theory about the coronavirus is that the icebergs tip which is very small as compared to the submerged iceberg represents the identified cases whereas the submerged iceberg represents the unidentified cases, misdiagnosed cases and the case which are vulnerable. Also, the COVID-19 can be the tip of the iceberg and lot more viruses may enter in human ecosystem due to encroachment in wildlife habitat. Therefore, all these factors are decoded and taken for due consideration in a comprehensive overview in this article.

\section{ABOUT SARS-COV-2 - STRUCTURE AND TRANSMISSION}

Coronaviruses are a different category that can cause mild to serious respiratory infections in humans, infesting several different species. Two highly pathogenic zoonotic coronaviruses, SARS-CoV and Middle East Air Coronavirus (MERS$\mathrm{CoV}$ ), occurred in people, respectively in 2002 and 2012, causing fatal respiratory disorders. New public health issues in the 21 st century were emerging coronaviruses. SARS-CoV-2 is a positive Single Strand RNA virus that causes serious human respiratory syndrome. Coronavirus 2019 (COVID-19) was a severe pandemic and between December 2019 and August 2020 more than 0.8 million lives were claimed. Coronaviruses can usually cause diseases of human and animal respiratory, gastrointestinal and central nervous systems which threaten human lives and cause economic loss. The coronaviruses are divided in alpha $(\alpha-\mathrm{CoV})$, beta $(\beta$ $\mathrm{CoV})$, gamma $(\alpha-\mathrm{CoV})$ and delta $(\mathrm{CoV})$ coronaviruses. Alpha and beta-COV can infect mammals and human viruses are genetically identical to $\beta$-CoV. SARS-CoV and SARS-CeV-2 are both placed in lineage B, which has approximately 200 virus sequences released, while MERS$\mathrm{CoV}$ is of line $\mathrm{C}$ which has approximately 500 virus sequences. The $\beta$-CoVs are further broken down by lineage $\mathrm{A}, \mathrm{B}, \mathrm{C}$ and $\mathrm{D}$ lineages. Coronavirus is one of the largest in all RNA viruses between 27 and $32 \mathrm{~kb} .(6)$

In a resident of Hubei, Central China, the first recorded coronavirus disease (Covid19) case in 2019 was notified on 17 November 2019. Wuhan, a new coronavirus that has killed more than 1800 and infected more than 70000 individuals within the first fifty days of the outbreak, recently exploded at the end of 2019 at the developing Chinese business center. It was confirmed that this virus was part of the beta coronavirus community. The new virus is known by Chinese researchers as Wuhan coronavirus or the new 2019 (2019-nCov). Viruses have been named as SARS-CoV-2 and COVID-19 by the International Taxonomy Committee $(\mathrm{ICTV})(7)$.

Coronavirus represents the broad family of RNA-positive, single-stranded viruses found in birds, camels, goats, cats, pigs and bats in a number of animals. In order to establish preventive measures to avoid the infection the source and transmission are necessary to identify. With SARS$\mathrm{CoV}$, the researchers were initially based as a central reservoir of infection on raccoon dogs and palm civets. However, the positive result for viral RNA detection only was shown by the insulated samples from the calves on the food market, indicating that the calves could be secondary hosts. Later on, the more dangerous carriers of these species are rhinolophide bats, which display no 
clinical signs of infection was also found(8).

The key means of transmission are the respiratory droplets; if he or she has contact with an infected person or any of his or her objects, like clothing, doorbells etc. SARS-CoV-2 may be transferred to a healthy person. Studies have shown that SARSCoV-2 can also be transmitted by aerosol (airborne transmission), but no specific neonatal analysis has been carried out (mother to child). Prior to the development of viral pneumonia, SARSCoV-2 was contained in saliva, blood, sputum, and urine and some patients had no pneumonia at all. Potential sources of SARS-CoV-2 infection are asymptomatic individuals who monitor current outbreak transmission dynamics. The international spread of COVID-19 accelerated from late February despite the weakening trend in China. Growing numbers of countries reported large clusters of infection. SARSCoV-2"s high transmission efficiency and international travel abundance enables COVID-19 to spread rapidly throughout the world. The global COVID-19 outbreak was formally identified as the pandemic by the WHO in 11 March 2020. As COVID19 has effectively been tracked in China since March, there have been sharp rises in the numbers of cases in Europe, the US and other areas. As of 11 March 2020, 216 countries and regions from all six continents had registered over 20 million cases of COVID-19 and more than 733,000 patients had died, according to the COVID-19 Center for System Science and Engineering dashboard at Johns Hopkins University. The United States is the nation with the most cases to date. This article explores the origin and mode of transmission of human coronaviruses worldwide. We also address the related infectivity and biological characteristics of SARS and MERS with a specific emphasis on COVID-19. Recently in the month of December 2020, news from United Kingdom suggested that new mutated strain of coronavirus has been reported and supposedly more virulent than the current strain which is already wreaking havoc all across the globe. Another new strain also has been reportedly registered in SouthAfrica. Countries learning from the mistakes hascancelled and ban all travel to and fro from these nations. The mutation of virus is definitely a cause of concern as the people movement are increasing as festive seasons are passing by. There lot of people are left vulnerable and clueless about the future course of the disease.(9)

\section{COVID-19 - INCUBATION PERIOD AND SYMPTOMS}

The incubation period of COVID-19 is not fixed for all the same but varies between 2 days to fourteen says depending upon the viral load age and the medical profile of the person. Symptoms generally starts to show after 4 to 5 days after exposure to the virus. The humoral and cell mediated immune response starts to counter the external invasion of the pathogen in the body. Symptoms include fever, cough, cold which are minor symptoms and it can worsen into major symptoms like loss of taste and smell, diarrhea, dyspnea, fatigue and so on. Th comorbidity is the factor in deciding the severity of the COVID-19 symptoms. As the comorbidity is the biggest decider of the clinical outcomes. The huge case fatalities that recently crossed the million mark and reaching to double of that figure is largely attribute to the comorbid condition of the patients admitted. (10)

\section{COVID-19 - AN ICEBERG PHENOMENON}

There are two ways to interpret the iceberg phenomenon. Both are closely related to COVID-19 and its dangerous consequences. The spread of the COVID19 and the spreading ability of the coronavirus is huge. Initially at the starting of the initial outbreak, it was limited to Wuhan city where the wet market of animals is located in china and supposedly the origin of the disease. Now almost more than 200 countries are severely affected by the pandemic. COVID-19 is the worst 
pandemic in terms of health outcomes and so far, the reason of over million and half casualties. In almost last 100 years no disease outbreak or epidemic was as lethal as COVID-19 and hence it created few fundamental questions. An iceberg phenomenon certainly give word to those questions. It describes the cases that are detected and can be referred to treatment further of certain disease and cases that are not detected, asymptomatic, pre symptomatic, false detection of cases and vast majority of cases that are not even tested for the disease. It is widely assumed that tested for COVID-19 cases are far less than actual number of cases. Asymptomatic cases account for major chunk of the actual number of cases of COVID-19. It is hard to test everyone but must be done gradually. Community surveillance can be used to counter this menace. We have successful example of SouthKorea where the testing strategy was extended to the last known person so as to hospitalize all the patients caring coronavirus infection before they spread the infection to larger masses. Lockdown and physical distancing restrictions were employed in many countries, particularly in India where it was implemented effectively and were harsh in nature. It also helped to certain extent temporarily but after that the number grew exponentially it is found to be ineffective(11). Therefore, chances of asymptomatic patients carrying the infection with to the places were increased. However, the government is ramping up the testing and ensuring that no person is left untested. As so far some of conclusions can be drawn from the coronavirus behavior and one of which is comorbidities can prove lethal when combined with the COVID-19 infection. And if undetected person but carrying the COVID-19 infection met with the comorbid person then the chances are that comorbid person may have to be hospitalized whereas another person may need not done with the same. After the lifting and easing of curbs such as movement restrictions and lockdown, the movement of people across the geography threatens the containment measures and mitigation strategies designed for the COVID-19 as transmission of the disease may speed up. Latest news about two new strain of mutated coronavirus emerging from United Kingdom and South Africa has created the wave of panic across the globe. The mutated strain is found to be more virulent than the previous viral strain which already has wreaked the havoc across the globe. It spreads many times faster and the symptom severity is however more or less comparable than the previous one. Although the alert about the new strain prompted aviation agencies around the world to restrict air travel to and fro from the country and governmental agencies has issued guidelines and standard operating procedure regarding the treatment of UK bound passengers returned back to their places. The undercurrent of the infection may be flowing as silent carriers which are left undetected(12).

\section{EFFECTS OF ICEBERG PHENOMENON}

The ice above the water surface in iceberg modeling of the COVID-19 infection only indicated the detected and tested cases and which are designated to be treated. The major portion of the iceberg is submerged under the water and is hidden. That part represents the asymptomatic cases, presymptomatic cases, cases which got no medical attention, and many such cases which are possible carrier of the disease. This includes vulnerable sections also which needs extra medical attention. If the iceberg's lower end becomes bigger then it would create another disaster if left unnoticed. Spreading ability of the undetected carrier is huge as he or she can participate in any occasion unintentionally transmitting the virus to other people causing the super spreading event. As festival season are approaching and chances are more people will change their places, it is important that they know, they are not contributing in the transmitting the 
disease. The testing strategy needs to be revamped and goals must be testing all the population in particular geographical area. Serological prevalence studies or sero surveys are done to check the prevalence of the disease in a particular area and see how many people have been infected in that particular area. Serology tests are employed to check the antibodies in persons particularly in specific geographical locations such as metro cities, urban and congested settlement where the chances of the transmission of the disease are high. The presence of antibodies specific to particular species means that the sampled person may have been exposed to the infection or currently undergoing one. Sampling techniques are used to study limited number of samples then the results are extrapolated to larger area according to mathematical modelling. Randomized trials are advised taking samples randomly at times. Small samples do not mean that the study is biased towards certain outcome but instead larger samples are taken when extremely high precision is needed. It does not affect the overall trend. WHO has issued guidelines about using serosurvey in eliminating measles and rubella. The seroprevalence in certain geographical areas can point towards increased spread of the disease. And authorities can be warned about modification in the containment strategy in that area. Events of mass public gatherings can be prevented from happening in that area to decongest and break the chain of the viral spread(13).

\section{COVID-19 IS ONLY THE TIP OF THE ICEBERG}

When Ebola outbreak broke out in African countries in late 1990's and initially it was not taken seriously. But as tribesman of certain tribes died continuously, then they got scared and even refused to stay in wild jungle. It was alsoan example bad human nature interaction. A wild gorilla was killed in jungle and eaten up by tribal people and most of them died after eating that gorilla instantly in few hours' others fell severely ill and taken to hospital. As the development is progressing and new ideas and innovation are coming up to how to utilize all the space on earth for humans use, it is becoming hard day by day to maintain biodiversity and rich heritage of wild jungles which are sometimes called lungs of the earth and prized possession of the earth(14). Poaching and hunting of exotic species for the human consumption is rampant and increasing rapidly as development is progressing. But there is a fine line of balance between nature and human venture that can be extended to certain parts which needs to be kept in mind and not disturbed. In case of coronavirus, the origin hypotheses suggest that balance is disturbed resulting in this world-wide pandemic that is currently haunting us at our doorsteps. Transmission of virus from bats to pangolins and then to humans is not a new chain. The exotic species or any wild species may contain thousands of such viruses harboring in them. They are safeguarded by functional immunity and they just act as carriers. They stay in wild and their habitat must remain untouched. Many tropical forests which are unexplored are exploited by humans and built road through them and various industrial activities are done around them. This may result the spillover effect by consuming such animals which harbors the virus that can potentially wipe out the humanity. This little spill may cause the pandemic like COVID-19. Researchers of particular field are not at all surprised by the vast expanse and negative consequences of the COVID-19 pandemic as they have already warned that the delicate balance must not be broken in the name of development. Some things should be left for themselves. Mixing of ecosystems may sometimes prove disastrous and fatal. Wet market all around the world should be regulated properly so as they cannot trade in exotic and endangered species particularly those which are confirmed to harbor various lethal viruses in them(15). Studies concerned to different indigenous aspects 
on preventing the spread of Covid were reported(16-20). Studies related to recommendations and protocols of infection control are available (21-25).

\section{CONCLUSION}

The pathophysiology of the coronavirus is new and yet to be studied completely. The structure and its behavior have been changing constantly and it needed to be analyzed closely. The transmission of the virus is a major challenge to stop therefore preventive measures should promoted and adopted wherever it is possible such as wearing of masks and maintaining safe minimum distance to break the chain of the transmission. The tip of the iceberg phenomenon is extremely important to study and if true there are huge number of cases that needs to be attended. Also, the COVID-19 is not the last pandemic that world has seen and there are many more viruses hidden in the deep wild. If the interaction between wildlife and humans are not sustainable and are meant to exploit only then it would be catastrophic in future too. The wildlife and environment need to be handled carefully and consumption of exotic and endangered species must be strictly avoided so as to avoid the spillover effects of various viruses from animals to humans. The tests for coronavirus must be increased and be more accessible from any point. Drive way testing facility must install in all the economic zones as the economy is opening up. The test results must be delivered as soon as possible so that the person concerned must know if they are tested positive or negative. Massive testing drive by testing each and every residents of the country must be undertaken so that the chances of slipping away some positive patients can be minimized. In case of COVID-19 the severity of the disease increases as the time after the infection or incubation period increases. The nongovernmental organization and civil society partnerships also can be taken so that to make it more holistic effort to mitigate the viral spread.

\section{REFERENCES}

1. Dushyant Bawiskar, Pratik Phansopkar, Ayurva Vilas Gotmare. COVID-19 Facets: Pandemics, Curse and Humanity. Int J Res Pharm Sci. 2020 Aug 6;11(SPL1):385-90.

2. COVID-19 Map [Internet]. Johns Hopkins Coronavirus Resource Center. [cited 2020 Dec 26]. Available from: https://coronavirus.jhu.edu/map.html

3. WHO Coronavirus Disease (COVID19) Dashboard [Internet]. [cited 2020 Dec 26]. Available from: https://covid19.who.int

4. Wise J. Covid-19: New coronavirus variant is identified in UK. BMJ [Internet]. 2020 Dec 16 [cited 2020 Dec 23];371:m4857. Available from: https://www.bmj.com/content/371/b mj.m4857

5. Guan W-J, Liang W-H, Zhao Y, Liang H-R, Chen Z-S, Li Y-M, et al. Comorbidity and its impact on 1590 patients with COVID-19 in China: a nationwide analysis. Eur Respir J. 2020;55(5).

6. Hu B, Guo H, Zhou P, Shi Z-L. Characteristics of SARS-CoV-2 and COVID-19.Nat Rev Microbiol. 2020 Oct 6;

7. Shereen MA, Khan S, Kazmi A, Bashir N, Siddique R. COVID-19 infection: Origin, transmission, and characteristics of human coronaviruses. J Adv Res [Internet]. 2020 Jul 1 [cited 2020 Dec 26];24:91-8. Available from: http://www.sciencedirect.com/science /article/pii/S2090123220300540

8. Tsang TK, Wu P, Lin Y, Lau EHY, Leung GM, Cowling BJ. Effect of changing case definitions for COVID-19 on the epidemic curve and transmission parameters in mainland China: a modelling study. Lancet Public Health [Internet]. 2020 May 1 [cited 2020 Dec 24];5(5):e289-96. Available from: https://www.thelancet.com/journals/l 
anpub/article/PIIS2468-

2667(20)30089-X/abstract

9. CDC. Coronavirus Disease 2019 (COVID-19) [Internet]. Centers for Disease Control and Prevention. 2020 [cited 2020 Dec 26]. Available from: https://www.cdc.gov/coronavirus/201 9-ncov/more/scientific-briefemerging-variant.html

10. CDC. Coronavirus Disease 2019 (COVID-19) - Symptoms [Internet]. Centers for Disease Control and Prevention. 2020 [cited 2020 Dec 26]. Available from: https://www.cdc.gov/coronavirus/201 9-ncov/symptomstesting/symptoms.html

11. Tip of Covid iceberg: Study [Internet]. [cited 2020 Dec 24]. Available from: https://www.telegraphindia.com/india /tip-of-covid-19-icebergstudy/cid/1779564

12. Magombedze G, Ngonghala $C$, Lanzas C. Evalution of the "Iceberg Phenomenon" in Johne's Disease through Mathematical Modelling. PloS One. 2013 Nov 7;8:e76636.

13. Yesudhas D, Srivastava A, Gromiha MM. COVID-19 outbreak: history, mechanism, transmission, structural studies and therapeutics. Infection [Internet]. 2020 Sep 4 [cited 2020 Dec 26]; Available from: https://doi.org/10.1007/s15010-02001516-2

14. WHO Director-General's opening remarks at the media briefing on COVID-19 - 7 September 2020 [Internet]. [cited 2020 Dec 26]. Available from: https://www.who.int/directorgeneral/speeches/detail/who-directorgeneral-s-opening-remarks-at-themedia-briefing-on-covid-19---7september-2020

15. Vidal J. "Tip of the iceberg": is our destruction of nature responsible for Covid-19? The Guardian [Internet]. 2020 Mar 18 [cited 2020 Dec 26]; Available https://www.theguardian.com/environ ment/2020/mar/18/tip-of-the-icebergis-our-destruction-of-natureresponsible-for-covid-19-aoe

16. Nisargandha, M.A., and S. Dadaraoparwe. "Spread of Coronavirus Disease 2019 (COVID-19) during the Lockdown in the Indian Population and Preventive Measures." International Journal of Research in Pharmaceutical Sciences 11, no. Special Issue 1 (2020): 328-32. https://doi.org/10.26452/ijrps.v11iSPL 1.2721 .

17. Deogade, M.S. "Agnihotra (Homa)-an Ayurveda Therapy in the Prevention and Control of Covid-19." International Journal of Research in Pharmaceutical Sciences 11, no. Special Issue 1 (2020): 304-9. https://doi.org/10.26452/ijrps.v11iSPL 1.2717 .

18. Gond, A.G., and R. Bhutada. "Concept of Dhoopana and Its Role in Prevention of Air Born Infection during COVID-19 Outbreak." International Journal of Research in Pharmaceutical Sciences 11, no. Special Issue 1 (2020): 963-66. https://doi.org/10.26452/ijrps.v11iSPL 1.3279 .

19. Patnaik, K.C., and D. Rajput. "Role of Antioxidant Herbs and Yoga Practices in Prevention of Infectious Diseases with Special Reference to Covid-19 Pandemic." International Journal of Research in Pharmaceutical Sciences 11, no. Special Issue 1 (2020): 317-22. https://doi.org/10.26452/ijrps.v11iSPL 1.2719 .

20. Bagde, K., B. Rathi, R. Rathi, P. Badwaik, and S. Khabde. "Role of Common Kitchen Remedies in Prevention of Infectious Diseases with a Particular Perspective of COVID19." International Journal of Research in Pharmaceutical Sciences 11, no. Special Issue 1 (2020): 1378-83. https://doi.org/10.26452/ijrps.v11iSPL 1.3647 . 
21. Deshpande, S.B., and S.D. Parwe. "The Review of Covid-19 Pandemic Disease." International Journal of Research in Pharmaceutical Sciences 11, no. Special Issue 1 (2020): 433-37. https://doi.org/10.26452/ijrps.v11iSPL 1.2806.

22. Dhole, P.D., V.K. Lohe, R.P. Kadu, S.C. Mohod, M. Meshram, and G.A. Thakare. "Post COVID-19 Protocol of Treatment, Radiologic Examination and Infection Control in Dentistry." International Journal of Research in Pharmaceutical Sciences 11, no. Special Issue 1 (2020): 1384-89. https://doi.org/10.26452/ijrps.v11iSPL 1.3664 .

23. Gaidhane, S., N. Khatib, Q.S. Zahiruddin, A. Gaidhane, S. Telrandhe, and P. Godhiwal. "Depression, Anxiety and Stress among the General Population in the Time of COVID-19 Lockdown: A Cross-Sectional Study Protocol."
International Journal of Research in Pharmaceutical Sciences 11, no. Special Issue 1 (2020): 360-64. https://doi.org/10.26452/ijrps.v11iSPL 1.2726 .

24. Ghate, V.C., S. Borage, and P. Shelotkar. "Covid-19 in Pregnant Women." International Journal of Research in Pharmaceutical Sciences 11, no. Special Issue 1 (2020): 430-32. https://doi.org/10.26452/ijrps.v11iSPL 1.2805

25. Gulrandhe, P., A. Sahu, C. Dandale, W.M. Naqvi, P. Phansopkar, and K. Kumar. "Repercussions of Mass Gathering: Covid-19 Pandemic." International Journal of Research in Pharmaceutical Sciences 11, no. Special Issue 1 (2020): 946-50. https://doi.org/10.26452/ijrps.v11iSPL 1.3242 . 